\title{
Emerging Technologies and the Contextual and Contingent Experiences of Ageing Well
}

\author{
Toni Robertson ${ }^{1}$, Jeannette Durick ${ }^{1}$, Margot Brereton ${ }^{2}$, Kate Vaisutis ${ }^{2}$, \\ Frank Vetere ${ }^{3}$, Bjorn Nansen ${ }^{3}$, and Steve Howard ${ }^{3}$ \\ ${ }^{1}$ Faculty of Engineering and Information Technology, \\ University of Technology, Sydney, Australia \\ ${ }^{2}$ Science and Engineering Faculty, Queensland University of Technology, Australia \\ ${ }^{3}$ Computing and Information Systems, The University of Melbourne, Australia \\ \{Toni.Robertson, Jeannette.Durick\}@uts.edu.au, \\ $\{$ M.Brereton, Kathleen.Vaisutis\} @qut.edu.au, \\ $\{\mathrm{F}$. Vetere, hansenb, showard\}@unimelb.edu.au
}

\begin{abstract}
Based on a series of interviews of Australians between the ages of 55 and 75 this paper explores the relations between our participants' attitudes towards and use of communication, social and tangible technologies and three relevant themes from our data: staying active, friends and families, and cultural selves. While common across our participants' experiences of ageing, these themes were notable for the diverse ways they were experienced and expressed within individual lives and for the different roles technology was used for within each. A brief discussion of how the diversity of our ageing population implicates the design of emerging technologies ends the paper.
\end{abstract}

Keywords: Ageing population, ageing well, social technologies, tangible technologies, diversity.

\section{Introduction}

We are engaged in a project that investigates sociophysical interaction conceptualised as the entanglement of tangible and social interaction. With commitments to phenomenological and participatory approaches, as well as the recognition that all human action is both embodied and situated, our project is grounded by the exploration of the roles that emerging social and tangible information and communication technologies can play in ageing well. This context provides the actual living bodies, objects and physical environments that such research depends on. It also responds to its pressing significance to many developed societies where governments and other agencies are seeking to evolve policies and strategies to provide appropriate, adequate and costeffective services to their ageing citizens within limited and tightening budgets. Design and use of new and emerging technologies can contribute to the alignment of the desires of ageing people to remain active and in control of their lives with the goals of governments to encourage healthy, active and financially independent senior citizens and so minimise their reliance on expensive government services (eg Andrews 2002). 
We have begun to explore this space where actual ageing bodies meet with new social and tangible technologies, as well as with still-developing social policies, through an initial series of scoping interviews with ageing people. This paper is not intended as a comprehensive discussion on the findings of those interviews (see Robertson et al. 2012 for a preliminary discussion of findings), nor is it an attempt to systematically challenge the myths and stereotypes that exist about older people. Instead, our interest is to explore the major issue that 'shouted' from our data: the diversity of our participants, which existed despite the limited demographic and the assumed homogeneity of ageing people that we encountered both in prevailing social attitudes and much of the research on ageing and gerontechnology (see Lindley, Harper \& Sellen 2008 for a literature review of this topic).

We begin by briefly describing the series of interviews before teasing out the areas of diversity and related richness that were both shared and defining of the lives of our participants. From there we explore the highly contextual and contingent ways some common aspects of ageing were experienced and expressed in the day-to-day lives of our individual participants and the role new and emerging technologies were playing in these experiences. We end the paper with a brief discussion of the implications such diversity has on the design of emerging technologies.

\section{The Interviews}

Scoping interviews are designed as a small, open corpus of loosely-structured interviews that are used to evaluate, ground and refine the initial understandings, assumptions and concepts of a research team in projects such as this one where the development of ethnographic understandings of the domain of intended use are an important part of the process (Robertson et al. 2012). Both their design and analysis were driven by the needs of the project as design research (Cross, 2007). This means that our concerns are less about exhaustive analysis of what currently exists and more about checking our assumptions, focusing the research team with shared understandings of what ageing well meant to those who were actually doing the ageing and so developing an informed orientation to the aims of the research project. The interviews were intended to provide a ground from which to investigate what might be technologies of value in the future and how we might initiate their design and uptake. They were designed to solicit both demographic and experiential data including fitness and activity levels, community and social engagement, use of and attitudes to various kinds of information and communication technologies and applications, future work and retirement plans, and current practices around keeping in touch with friends and families. Each participant was also asked to describe what ageing well meant to them and to add anything else about ageing that they felt relevant to our project.

Twenty interviews from four groups of ageing people have been completed, transcribed and analysed. We interviewed five members of each group. The groups were chosen to represent an aspect of ageing of particular relevance to the overall project: maintaining health and mobility, community engagement, and social and family relationships. We sought people aged between 55 and 75 who were still very active, 
including some still in full time employment, some working part time and some who were retired from paid employment but engaged in community activities of various kinds. Participant contexts included patients in a community rehabilitation hospital in Sydney who had joint replacement surgery 10-14 days prior to their interview; members of an ethnic community organisation in the Illawarra district of NSW; members of large national and voluntary community service organisations in Brisbane and a group who, for various reasons, were childless. Men and women participated equally in the interviews and the group included people from cities, regional and rural areas of Eastern Australia.

The interviews were completed and transcribed in batches with initial analysis of the first ten used to generate areas of attention that could be further addressed in the remainder. The analysis of the full series included combining and comparing different participants' contributions to each area of questioning as well as identifying both commonalities and areas of difference that might be more thoroughly explored by field study and iterative prototyping in the remainder of the project. In our analysis we were mindful of Star's recommendations to listen for the special language used by the participants and for anything that appeared 'strange, weird and anomalous' (Star 2010, p. 605). The first recommendation maps closely to the central HCI design principle expressed by variations of 'Know the user population', while the 'strange, weird and anomalous' can help us develop insights into the diversity of our participants, the richness of their experience and relationships, and how these might refine our focus on the roles social and tangible technologies might play in ageing well.

\section{The Diverse Experiences of Ageing and Technology Use}

Summarised very broadly, our participants' views of what ageing well meant to them were remarkably similar. Good health, with a particular emphasis on mobility and fitness; social agency in their interactions with family and friends; independenceincluding both physical and financial independence in their daily lives; and some kind of ongoing work and/or community involvement were repeatedly identified as central to the maintenance of current and future well-being. Our participants all expressed their desire to maintain for as long as possible, their capacities to actively experience the areas of their lives that defined their shared sense of ageing well.

However, while our participants' views of ageing well were very consistent, their actual ageing bodies were not. Their bodies were the bodies of people who had led long lives. They were old enough for their various individual genetic, cultural and environmental influences to have expressed themselves, along with the inscriptions made on their bodies by their actual life experiences, such as the work they did, how well they had 'looked after themselves', their access to health care, good food and a safe environment, the communities in which they lived and the kinds of social activities, cultural mores and expectations these provided, as well as various random life events and accidents. So what it would mean and require for each participant to maintain good health, mobility and fitness varied enormously in practice. While the desire to remain active was also common, the activities our participants wanted to continue 
were similarly varied. And while all our participants wanted to maintain their social agency and ongoing relationships with families and friends, their social networks and how they were experienced and managed were very different.

Our participants were already using information and communication technologies and had learned to use them at work or when they had recognised a need or advantage to do so. The use of word processing, email and various web services, such as online banking was common. Given our focus on the roles that social and tangible technologies might play in ageing well, our participants' engagement with and attitudes towards new and emerging technologies were as contextually and contingently defined as other aspects of their ageing selves. In the remainder of this section we explore the relations between our participants' attitudes towards and use of communications, social and tangible technologies and three relevant themes from our data that, while common across our participants, were notable for the diversity of their experience and expression. These themes are: staying active, friends and families, and cultural selves.

\subsection{Staying Active}

Maintaining an active lifestyle was cited by all participants as being central to ageing well and framed as being part of a cycle of habits and behaviours, including social activities and physical exercise that all impacted one another. Maintaining good health was considered central to keeping mobile and maintaining the social agency and physical independence that each of our participants valued so highly:

- "your body deteriorates a lot quicker if you don't keep moving"

- "poor health stops you living well. It stops your quality of life".

All our participants recognised that their bodies had changed with age in ways that had affected their mobility and the activities they enjoyed. Several were dealing with recent cancer scares and most had some kind of age-related health condition such as diabetes, arthritis, high blood pressure and general aches and pains. But the health effects of ageing were very specific to each individual; impacted each of them in distinct and diverse ways and each responded to them differently. One participant told of the shift from soccer playing and a life of physically demanding jobs to games of billiards and extensive volunteer work at his local community club. Another longed to enjoy gentle travel and gardening after a working life involving a great deal of hectic, work-related travel and active sports that had led to early joint degeneration. Another still played tennis regularly (but no longer in competition), watched cricket instead of playing it and walked a great deal, including daily walking a dog that was jointly owned with several other similarly-aged friends, who also regularly walked him.

At least half our participants were still working either full time or in various stages of reducing their work hours and moving into full retirement. Those who were fully retired were active in various kinds of community and volunteer work even holding leadership positions in their various community groups. The activities our participants engaged in varied widely and included (among just twenty people): gardening, sport (eg golf, tennis, pistol shooting and bowls); explicit exercise (eg cycling, dancing, hydrotherapy, aerobics, gym programmes, swimming, walking-alone, with others or 
with pet/s); playing chess, Scrabble, billiards and single-user computer games; actively contributing to community organisations and community projects; travelling (domestically and internationally)_individually, together or in larger organised groups (eg. cruises, bicycle and walking tours); taking a caravan around Australia; studying, both formally and informally; and engaging in a rich and varied range of social interactions with family and friends. The common element among all participants and their chosen activities was their desire to maintain their capacity to continue them.

Only one of our participants reported using any kind of technology as part of staying physically active - in this case a mobile app was used to record speed, distance, energy consumed etc during daily walks. Most participants had some knowledge, even positive experiences, of console games gained via interactions with their children and/or grandchildren. However, none were interested in acquiring a game console of their own. Most participants explained they were "too busy" for games. Several added they were not interested "I'm not a games person; not even of the board variety" while others indicated that if relevant they might be interested. For example, one had played online Scrabble with his adult child as an informal way to stay connected while another reflected that he would like "someone to play a game of chess with". But tangible technologies involving active bodily movement as input remained largely unfamiliar and unused among our participants at the time of the interviews.

\subsection{Friends and Families}

Our participants all had families and networks of friends that varied in their conventionality, size, geographic spread, frequency of interaction and emotional connectedness. Most participants had children and grandchildren; some had been divorced, others widowed and some had remarried and/or settled with new partners. Others still had never married yet maintained close, large and supportive networks of friends: "I've never been a family person. I've always been more into friends".

Participants noted that it wasn't only their bodies that were affected by the changes ageing brings, but also their relationships with other people. Staying active was central to maintaining these relationships. One participant, a retired semi-professional golfer said: "Physical activity is my number one priority [...] I know that grandchildren will be on the way. I want to be able to physically be with them. I don't want them looking at grandma sitting in a chair and who can't do anything, because I want to enjoy them." Another commented: "whilst we can still interact with the young ones we will. I like to get on the floor with them but I'm not as able as I was two years ago." Others were concerned about needing to be cared for by friends and families or noted the changing needs of their ageing friends: "old friends who really do decline or change or have to move or that sort of thing. Dealing with that is something that I was not prepared for".

Phones, both landline and mobiles were the usual means of keeping in touch with others. Only one participant did not have his own mobile phone but he used his wife's mobile when necessary. Another used his mobile very infrequently, mainly when travelling, but used email intensely for both work and social contact. For others, 
mobile phones were enmeshed in their everyday lives. SMS messages were popular especially within close relationships: "I will SMS forever and a day, particularly to the kids". Email use was frequent and well-established. All participants had heard of Skype with around half of them using it to maintain contact with distant family and friends. One was using it very frequently to maintain contact with a close friend in another country who was very ill. Facebook and even LinkedIn were also used to maintain contact with distant relatives and friends. Another was following a blog written by an old school friend who was travelling around the country in a caravan.

Physical distance between our participants and their geographically dispersed friends and family was reflected in varying ways in the regularity of interaction and the types of technology used. Phones, SMS and email were the first choices for close and regular contact-both for organising social activities and/or for just keeping in touch that is, maintaining relationships - but these were complemented by the use of Skype and Facebook for maintaining contact with those further away and with larger social groups such as wide family relationships and old school friends: "for staying in touch with people. Even if it's just to see what they're doing, as opposed to actually communicating with them." We did not find any examples where our participants had used Facebook for forming new friendships or engaging with apps or marketing.

\subsection{Cultural Selves}

Ageing people, by definition, have long embodied histories; they have lived though many relationships and many changes over time, not just with people but with places and objects including a great variety of technologies. Their social identities have been produced and shaped by the lives they have led. All our participants had their own very specific histories that shaped how they defined and lived their social roles, their values and the priorities of their current lives. Among our participants there were still differences in how communication technologies were used, particularly among our older participants who had migrated to Australia as young adults. Aspects of the cultural self that we discuss here pertain to cultural origins, life histories, gender roles and generation.

All participants noted the importance of family and friends. Some of the participants, who had migrated from Europe, had large, extended families with many members still living overseas. The group from the Illawarra-based community club were skewed towards the older end of our demographic and shared a common ethnic and cultural identity. Traditional roles of husband and wife seemed stronger within this group though even here there were still some anomalies. For example, in one household, the husband used a variety of communication technologies regularly to keep in touch with family and organise get-togethers. This included using Facebook and videoing family events, editing these and then copying the final product to DVDs that he posted to relatives abroad. On the other hand his wife, who claimed to be uncomfortable with technology, used her mobile phone extensively for immediate and frequent social contact and organisation with close relatives and friends. 
Well, we've both got a mobile phone, and of course I've got the Internet too. I keep in contact with SMS and emails. Most of our kids work. The way to get to them is to send them a message-SMS 25 cents. So even if they are working it doesn't matter. My wife doesn't use SMS. She rings. She's not a real tech ..."

But in another household within the same group, the female participant possessed the technical skills (aided by her granddaughter's guidance) and her husband, whose health was poor, relied on her to organise and maintain frequent contact with their extended family.

Differences in technology use and attitudes to it also reflected the type of work our participants did or had done. For example, one participant, a farmer who also ran a small earth moving business, explained: "<female partner $>$ does most of my computer work for me. I sit there and dictate and she writes it out. It's a typing issue . . I find it a bit frustrating to sit down at a computer". He had always done his paperwork manually but had learned to use internet banking, to search for information online and to read email. He understood and could manage the computers that were part of his earthmoving equipment and had learned to maintain home's Internet connection despite living in an area with frequent lightning strikes. It was his partner who did most of the emailing and used both Skype and Facebook: "<female partner > uses Facebook, but I would never go on Facebook; I reckon it's a waste of bloody time." Among the younger participants and the city-dwellers there were no obvious gender differences in either familiarity with or use of the different technologies.

Our participants readily acknowledged generational differences in technology usage within their own families and circles of friends-particularly the use of mobile phones and Facebook. While this was at times accompanied by dismissive comments about Facebook from some of the male participants, for most it was a simple acknowledgement of technological change and generational differences. One participant, after commenting on his grandchildren's addiction to Facebook, added "if they haven't got a telephone, it's like cutting one of their arms off or something. They're lost'. But later in the interview, commenting on his current use of a mobile phone and his own youth, remarked: "I don't know how people used to get on then without phones and iPods or whatever they call them".

\section{Discussion}

The demographic for our interviews was a relatively narrow one: white, middle-class, between the ages of 55 and 75 and living in the eastern states of Australia. All participants shared a strong sense of what ageing well meant to them, that is, one that privileged maintaining health, mobility and independence, and active engagement with their families, friends and local communities. Yet within this group of peoplechosen because they fitted an 'ageing' demographic-some were still working, some were semi-retired and others fully retired; some were very computer literate while others were comfortable only with (mobile) phone use and basic email; all had very different physical and/or personal needs that were being managed in a wide range of ways and their reasons for engaging with technologies, the selection of which technologies to use and what they were actually used for varied widely. 
Our participants made choices about the technologies they used based on specific needs, relevance and the availability of supporting infrastructure. They had already appropriated a number of communications technologies into their everyday lives and were in various stages of engaging with newer social technologies. There were different levels of familiarity with some of the newer tangible technologies but little interest, at this stage, in expanding their use of those currently available. Most of all, our interviews provided a snapshot of the ongoing appropriation by our participants of new technologies that were not specifically age-related but part of the general social, technological and physical infrastructure in which ageing people live. And they reminded us that our potential users' familiarity with ICTs is dynamic, diverse and unbounded. Most importantly our findings highlight the diversity of the ageing population and the need for technology compatible with both diverse use and diverse users.

Diversity within our chosen demographic was multi-dimensional and often unpredictable, confirming the need to continue to question common assumptions about both ageing and the use of new and emerging technologies by ageing people. It was clear that our participants lived their lives within the range of norms and expectations available within their culture, even as they insisted on negotiating their own pathways through ageing. In the process they were actively reinterpreting these same cultural norms and expectations. Importantly for our current context, the recognition of the specificity of ageing bodies and the activities that are available to them-including the appropriation of new and emerging technologies - foregrounds the further recognition that ageing people have always been and will always remain embedded within their ever-changing social and cultural worlds. Indeed it is that embeddedness that they are seeking to maintain as they continue to age.

Acknowledgements. This research is funded by the Australia Research Council Discovery Grants Program DP110101999. We are grateful to our participants for their contribution.

\section{References}

1. Andrews, K.: National Strategy for an Ageing Australia. Commonwealth of Australia, ACT (2002)

2. Cross, N.: Designerly Ways of Knowing. Birkhäuser Architecture (2007)

3. Hughes, J., King, V., Rodden, T., Andersen, H.: Moving out from the control room: ethnography in system design. In: Proc. CSCW 1994, pp. 429-439. ACM (1994)

4. Lindley, S.E., Harper, R., Sellen, A.: Designing for elders: exploring the complexity of relationships in later life. In: Proc. BCI HCI Conference, vol. 1, pp. 77-86 (2008)

5. Robertson, T., Durick, J., Brereton, M., Vetere, F., Howard, S., Nansen, B.: Knowing Our Users: Scoping Interviews in Design Research with Ageing Participants. In: Proc. OZCHI 2012, CHISIG/ACM, pp. 517-520 (2012)

6. Star, S.L.: This is Not a Boundary Object: Reflections on the origin of a Concept. Science. Technology and Human Values 35(5), 601-617 (2010) 